\title{
BMJ Open Dietary intake and factors influencing eating behaviours in overweight and obese South Asian men living in the UK: mixed method study
}

Amir Emadian, ${ }^{1}$ Clare $Y$ England, ${ }^{2,3}$ Janice L Thompson ${ }^{1}$

To cite: Emadian A, England CY, Thompson JL. Dietary intake and factors influencing eating behaviours in overweight and obese South Asian men living in the UK: mixed method study. BMJ Open 2017;7:e016919. doi:10.1136/ bmjopen-2017-016919

- Prepublication history for this paper is available online. To view these files please visit the journal online (http://dx.doi org/10.1136/bmjopen-2017016919).

Received 20 March 2017 Revised 18 May 2017

Accepted 13 June 2017

\section{CrossMark}

${ }^{1}$ School of Sport, Exercise and Rehabilitation Sciences, University of Birmingham, Birmingham, UK

${ }^{2}$ Centre for Exercise, Nutrition and Health Sciences, University of Bristol, Bristol, UK

${ }^{3}$ Bristol Biomedical Research Unit in Nutrition, Diet and Lifestyle, National Institute for Health Research, University Hospitals Bristol Education and Research Centre, Bristol, UK

\section{Correspondence to} Amir Emadian; ahe299@bham. ac.uk, amir.ptraining@gmail. com

\section{ABSTRACT}

Objective It is widely recognised that South Asian men living in the UK are more likely to develop type 2 diabetes mellitus (T2DM) than their white British counterparts.

Despite this, limited data have been published quantifying current dietary intake patterns and qualitatively exploring eating behaviours in this population. The objectives of this study were to (1) assess diet, (2) explore perceptions of T2DM, (3) investigate factors influencing eating behaviours in overweight/obese South Asian men and (4) determine the suitability of the UK Diet and Diabetes Questionnaire (UKDDQ) for use in this population.

Setting Community-based setting in the Greater London, UK area.

Participants South Asian men aged 18-64 years, with a body mass index of over $23.0 \mathrm{~kg} / \mathrm{m}^{2}$, not previously diagnosed with T2DM.

Methods A cross-sectional mixed-methods design, including assessment of dietary intake using UKDDQ $(\mathrm{n}=63)$, followed by semistructured interviews in a purposive sample $(n=36)$.

Results UKDDQ scores indicated $54 \%$ of participants had a 'healthy' diet with a mean sample score of $3.44 \pm 0.43$ out of a maximum of 5 . Oily fish consumption was low (1.84 \pm 1.85$)$. Body weight was positively associated with a high-added sugar subscore $(r=0.253, p=0.047)$, with $69.8 \%$ of the men having 'unhealthy' intakes of sugar-sweetened beverages. Cultural commitments (eg, extended family and faith events), motivation and time were identified as key barriers to dietary change, with family support an important facilitator to making healthy dietary changes. Participants stated that UKDDQ was suitable for assessing diets of South Asians and made suggestions for tailoring questions related to rice consumption, providing examples of Indian sweets, and including ghee as a fat source.

Conclusion Many of the areas of dietary improvement and factors affecting eating behaviours identified in this study are similar to those observed in the general UK population. Consumption of sugar-sweetened beverages in particular was high; given the association between their consumption and the risk of T2DM, this should be an area of primary focus for healthcare professionals. Nevertheless, there are sociocultural factors unique to this population that need to be considered when designing culturally specific programs to reduce the development of T2DM in this high-risk population.
Strengths and limitations of this study

- Use of mixed methods to investigate dietary intake and eating behaviours in overweight/obese UK South Asian men.

- Use of newly developed UK Diet and Diabetes Questionnaire to assess diet.

- Sample included participants from a wide range of religious and ethnic backgrounds.

Relatively small sample size.

\section{BACKGROUND}

South Asians are the largest ethnic minority in the UK, representing $4 \%$ of the total population. ${ }^{1}$ It is widely recognised that South Asian men living in the UK have significantly higher rates of type 2 diabetes mellitus (T2DM) compared with their white British counterparts. ${ }^{2-4}$

Although the exact cause of this increased risk for T2DM is not fully elucidated, it is theorised that a combination of genetic factors and the adoption of a 'Westernised' lifestyle, including adopting new dietary practices in place of previous traditional practices coupled with reductions in physical activity, are primary contributors. ${ }^{5-7}$ Despite the recognition of the critical role of dietary intake and eating behaviours in increasing T2DM risk, there are limited number and scope of papers published that have quantified dietary intake and explored factors influencing eating behaviours in South Asian men living in the UK. Previous studies of South Asians have focused on measuring individual nutrient intakes as opposed to assessing diet as a whole ${ }^{8}$ others have focused only on children ${ }^{9}$ or women. ${ }^{10}$ The few studies involving men are relatively old ${ }^{11}$ or in exclusively Muslim populations. ${ }^{12}$ Thus, there are some existing gaps in the literature, which this paper attempts to fill. 
A recently published systematic review reported that there has been limited effectiveness in changing dietary practices in South Asian populations. ${ }^{13}$ To effectively improve the diets of any population, it is vital to understand what individuals are eating and what key factors influence their dietary behaviours. Therefore, to inform the development of effective, culturally appropriate interventions to change dietary intake among South Asian men, more research needs to be conducted to assess these behaviours and the factors influencing them.

The aim of this mixed-method study was to increase our understanding of dietary intake and related behaviours among overweight and obese South Asian men living in the UK by (1) quantifying food intake and dietary behaviours using a newly validated food frequency questionnaire specifically developed for adults at risk for T2DM and (2) using semistructured interviews to explore the factors influencing eating behaviours and to determine whether the UK Diet and Diabetes Questionnaire (UKDDQ) is a suitable tool for assessing dietary intake in this population.

\section{METHODS}

\section{Study design and participants}

The current sample was the same as that examined in a previous study, which investigated physical activity and sedentary time. ${ }^{14}$ A cross-sectional mixed-method study design was used to assess the dietary intake of a sample of South Asian men at risk of developing T2DM (as defined by their overweight/obesity status and ethnicity) and to understand the key factors that influence their dietary choices and eating behaviours. Maximum variation sampling was used to purposively recruit a relatively small sample of participants from a wide range of demographics to yield in-depth information about the phenomenon being studied. ${ }^{15}$ Recruitment centred on building close ties with communities by visiting mosques, temples and community centres in the Greater London area, to discuss the research with community leaders. This was followed by advertising in local newsletters and running diabetes awareness days at the various temples to engage with members of the community.

Participants were eligible to take part if they were between the ages of 18 and 65 years, had a body mass index (BMI) of $\geq 23.0 \mathrm{~kg} / \mathrm{m}^{2}$ and were fluent in English. From October 2015 to April 2016, 63 participants were recruited, with data collection conducted during a single visit, taking place either at the participant's home or in a private location at their place of work. All participants provided written consent to take part; the study was approved by the ethical review committee of the University of Birmingham (reference no ERN_15-0518).

During the data collection visit, demographic, anthropometric, resting blood pressure and dietary intake data were collected, followed by a semistructured interview.

\section{Demographic data}

Sociodemographic data were collected using a self-report questionnaire. Postcodes were used to generate an Index of Multiple Deprivation (IMD) rank, which is an indicator of level of deprivation in England. ${ }^{16}$

\section{Anthropometric data and blood pressure}

Participants' height was measured (to the nearest $0.5 \mathrm{~mm}$ ) using the Seca 213 Stadiometer, weight was measured (to the nearest $0.01 \mathrm{~kg}$ ) using the Seca 899 Digital Scale (Seca, Birmingham, UK) and BMI in $\mathrm{kg} / \mathrm{m}^{2}$ was calculated. Waist circumference was measured at just above the umbilicus using a standard tape measure (to the nearest $0.5 \mathrm{~cm}$ ). Resting blood pressure was recorded to the nearest $\mathrm{mm} \mathrm{Hg}$ using the Omron M10-It monitor (Omron, Milton Keynes, UK), prior to 5 min of seated rest. All measurements were taken and recorded three times, with mean of the two closest measures taken as the final value.

\section{UK Diabetes and Diet Questionnaire}

UKDDQ is a 25-item questionnaire designed to assess diet and dietary behaviours in adults with, or at risk for, T2DM. It has been shown to be a reliable and valid measure of diet when compared with 4-day food diaries. ${ }^{17}$ An interviewer-administered version of the questionnaire was used to ensure accurate data entry and provide the opportunity to discuss both quantitative and qualitative aspects of dietary intake with participants.

\section{Semistructured interviews}

A purposive subsample of 36 participants was invited to take part in individual, semistructured interviews, conducted at the end of the data collection visit. Participants were purposively selected to provide maximum variation across age, ethnicity, faith, years living in the UK and level of deprivation. Participants were interviewed until data saturation was reached. An open-ended interview guide was used to inform the discussions, examining participants' perceptions of T2DM, the importance of dietary intake in preventing T2DM, barriers and facilitators to making dietary changes and any sociocultural factors influencing dietary changes. Participants where also asked whether they felt that UKDDQ was suitable for people from a South Asian background and whether any areas of the questionnaire needed to be improved or tailored to optimise their use in this population. The interview schedule was pilot tested with three South Asian men prior to commencing the study; further adjustments were made to the schedule throughout the data collection period using an iterative process. All interviews were audio-recorded and transcribed verbatim. All interviews were conducted in English.

\section{DATA REDUCTION AND STATISTICAL ANALYSIS Scoring and coding of the UKDDQ}

Of the 25 items on the questionnaire, 20 of the questionnaire items contributed to the overall score. Each of the 
20 items has six categories for the participant to choose from, corresponding to the participant's frequency of consumption for that particular item. The researcher then scored the questionnaire by following the UKDDQ scoring protocol by providing a corresponding letter relating to the chosen answer for frequency of consumption ranging from an $\mathrm{A}$ (healthiest choice) to an $\mathrm{F}$ (least healthiest choice). Hence the final score shown to the participant revealed how many A's, B's, C's, D's, E's and F's the participant achieved out of the possible 20, informing them that A's and B's are 'healthy choices,' C's and D's are 'less healthy choices' and E's and F's are 'unhealthy choices.' For the purpose of data analysis, the answers from each of the questionnaire items were re-coded into numerical values by applying the following codes: $\mathrm{A}=5, \mathrm{~B}=4, \mathrm{C}=3, \mathrm{D}=2, \mathrm{E}=1, \mathrm{~F}=0$. The mean UKDDQ score for each individual was then calculated from the 20 questionnaire scores, giving a final score ranging from 0 to 5 . Separate subscores were calculated by summing appropriate items for 'high-saturated fat' (full-fat spread, high-fat cheese, processed meat, savoury pastry and milk), 'high fibre' (vegetables, fruit, high-fibre bread and highfibre cereal) and 'high-added-sugar foods' (cakes and biscuits, confectionary, sweet drinks).

\section{Quantitative data analysis}

As the demographic data and the mean UKDDQ scores were not normally distributed, a two-step approach was used to normalise the data before statistical analysis was conducted,${ }^{18}$ including transforming the variable into a percentile rank, followed by applying an inverse normal transformation to the results derived from the first step. Descriptive analyses were conducted for all variables, including mean UKDDQ score and scores for each individual questionnaire item. Pearson's correlations were used to explore relationships between mean UKDDQ score and demographic variables. Spearman Rho correlations were used to explore the relationships between individual questionnaire items and demographic variables. Partial correlation analysis was used to determine the relationships between UKDDQ scores and demographic variables while controlling for country of birth and self-reported level of English literacy. One-way ANOVA analysis was conducted to determine any significant differences in mean UKDDQ between the demographic variables of levels of education or levels of English literacy. In order to ensure sufficient numbers, some groups were collapsed into larger categories; for country of birth ('UK', 'India' and 'Pakistan/Bangladesh'), levels of English literacy ('excellent', 'good' or 'fair/poor') and levels of education ('university/higher education', 'college' and 'secondary school or below'). Multiple linear regression (using the enter method) was used to examine whether sociodemographic variables (age, waist circumference and IMD rank) were predictive of mean UKDDQ score. A $\mathrm{p}$ value of $<0.05$ was interpreted as providing some evidence for a relationship between variables. ${ }^{19}$ Student's t-tests were used to test for any differences between key demographics of the full sample and the purposive subsample that participated in interviews, to determine if the subsample was reflective of the study sample. All statistical analyses were conducted using IBM SPSS statistical analysis software package (version 22.0).

\section{Qualitative data analysis}

Direct content analysis was used as the method for analysing the transcribed interviews. This approach is suitable for qualitative data analysis when there is already pre-existing research on the phenomenon being investigated. ${ }^{20}$ As there is research on enhancing diet for health promotion, along with limited evidence exploring barriers to making dietary changes in South Asian men, ${ }^{21}{ }^{22}$ this qualitative analysis method was deemed most appropriate. The existing published research also steered the process for constructing the interview guide. Throughout the process of developing the interview guide, major themes and concepts developed, and these were then used as the main coding categories for analysis. All transcripts were initially coded using the main coding categories by AE, with a selection of transcripts being coded by a second researcher (CYE) to confirm agreement in coding. Data that did not map onto the initial categories were classified as a new category. Once the final coding categories were determined, the transcripts were re-examined and final coding categories agreed by all authors.

\section{RESULTS}

\section{Quantitative results}

All 63 participants completed the UKDDQ and were included in the analysis, with all 36 participants who were invited to be interviewed agreeing to take part (the subsample). The mean age of the sample was $44.83 \pm 9.90$, with a mean BMI of $28.06 \pm 4.15 \mathrm{~kg} / \mathrm{m}^{2}$ (table 1). Student's t-tests found no differences between the full sample $(n=63)$ and the subsample $(n=36)$ for demographics, anthropometrics and mean UKDDQ score. Most participants were university educated $(81 \%)$ and had excellent levels of self-reported English literacy (58.7\%). The majority were Indian $(87.3 \%)$ and Hindu (50.8\%).

Table 2 summarises the results from the UKDDQ, showing average total scores and individual questionnaire item scores. Mean total UKDDQ score for the full sample was $3.44 \pm 0.43$ with a median total UKDDQ score of 4 (IQR, 3-4). Results showed that $54.0 \%$ of the participants had a median score in the healthy range (four or more). Mean UKDDQ scores were not correlated to demographics or anthropometrics (data not shown), although individual questionnaire items and the high-added-sugar foods subscale showed some evidence for a relationship (table 3). Partial correlation analysis revealed no significant correlations between the UKDDQ score and any of the demographic and anthropometric variables when controlling for country of birth and self-reported level of English literacy. One-way ANOVA analysis indicated no significant differences in mean UKDDQ score between 
Table 1 Demographic and anthropometric characteristics for 63 South Asian men participating in the study

\begin{tabular}{llll}
\hline Characteristic & Mean & SD & Range \\
\hline Age (years) & 44.83 & 9.90 & $25-64$ \\
\hline BMI (kg/m²) & 28.06 & 4.15 & $23.13-46.22$ \\
\hline Weight (kg) & 81.15 & 11.53 & $59.8-132.0$ \\
\hline Height (cm) & 170.84 & 6.11 & $157.70-185.90$ \\
\hline $\begin{array}{l}\text { Waist circumference } \\
\text { (cm) }\end{array}$ & 99.73 & 10.44 & $83.50-136.0$ \\
\hline Systolic BP (mm Hg) & 128.22 & 15.19 & $99.00-184.00$ \\
\hline Diastolic BP (mm Hg) & 84.78 & 9.38 & $63.00-113.00$ \\
\hline IMD rank & 16661.45 & 9470.80 & $2403-32823$ \\
\hline Country of birth, & & & \\
n (\%) & & & \\
\hline UK & $10(15.9)$ & & \\
\hline India & $45(71.4)$ & & \\
\hline Pakistan & $1(1.6)$ & & \\
\hline Bangladesh & $7(11.1)$ & & \\
\hline Ethnicity, $\mathrm{n}(\%)$ & & & \\
\hline Indian & $55(87.3)$ & & \\
\hline Pakistani & $1(1.6)$ & & \\
\hline Bangladeshi & $7(11.1)$ & & \\
\hline Faith, $\mathrm{n}$ (\%) & & & \\
\hline Hindu & $32(50.8)$ & & \\
\hline Sikh & $18(28.6)$ & & \\
\hline Muslim & $9(14.3)$ & & \\
\hline Hare Krishna & $2(3.2)$ & & \\
\hline Buddhist & $2(3.2)$ & & \\
\hline Education, $\mathrm{n}$ (\%) & & & \\
\hline University/higher & $51(81)$ & & \\
\hline education & & & \\
\hline College & $6(9.5)$ & & \\
\hline Secondary school & $4(6.3)$ & & \\
\hline Primary school & $1(1.6)$ & & \\
\hline No qualifications & $1(1.6)$ & & \\
\hline Sef-reportd & & \\
\hline
\end{tabular}

Self-reported English

literacy, $\mathrm{n}(\%)$

\begin{tabular}{|c|c|}
\hline Excellent & $37(58.7)$ \\
\hline Good & 18 (28.6) \\
\hline Fair & 7 (11.1) \\
\hline Poor & $1(1.6)$ \\
\hline \multicolumn{2}{|c|}{$\begin{array}{l}\text { Self-reported health, } \\
\text { n (\%) }\end{array}$} \\
\hline Excellent & $9(14.3)$ \\
\hline Good & $37(58.7)$ \\
\hline Fair & $16(25.4)$ \\
\hline Poor & $1(1.6)$ \\
\hline
\end{tabular}

Taking prescribed

medication, $\mathrm{n}(\%)$

\begin{tabular}{|c|c|c|c|}
\hline Characteristic & Mean & SD & Range \\
\hline Yes & 27 (42.9) & & \\
\hline No & $36(57.1)$ & & \\
\hline \multicolumn{4}{|l|}{$\begin{array}{l}\text { Taking BP } \\
\text { medication, n (\%) }\end{array}$} \\
\hline Yes & $16(25.4)$ & & \\
\hline No & 47 (74.6) & & \\
\hline
\end{tabular}

BP, blood pressure; IMD, Index of Multiple Deprivation.

the demographic variables of country of birth, levels of education or levels of English literacy $(\mathrm{F}(2,60)=2.423$, $\mathrm{p}=0.075 ; \quad \mathrm{F} \quad(2,60)=1.042, \quad \mathrm{p}=0.359 ; \mathrm{F} \quad(2,60)=0.396$, $\mathrm{p}=0.674$, respectively). Multiple linear regression analyses of sociodemographic variables as predictors for mean UKDDQ score resulted in no significant models.

\section{Qualitative results}

Figure 1 illustrates the final coding matrix of the key factors affecting dietary behaviours as reported by participants in qualitative interviews.

The following sections describe the findings, supported by representative quotes.

\section{WHAT IS T2DM?}

When asked about their perception of T2DM, most participants displayed some form of understanding as to what the condition was. However, 4 out of the 36 participants (11.1\%) stated that they did not know. Of those who did have an understanding, most made reference to having high 'sugar' levels in the body:

I think when you start getting the sugar issues or the problem where you have the high sugar in your blood. That is where your Type 2 diabetes starts. 47 years, Indian, Hindu, living in the UK for 16 years)

Participants also contextualised T2DM from their understanding of the symptoms relating to the condition:

Yes, I think that diabetes affects vision. It affects, um, the, the mass around the stomach and possibly swelling at the feet as well. (58 years, Indian, Hindu, living in the UK for 54 years)

Approximately one-third of participants mentioned they had an immediate relative who had T2DM and therefore had seen the symptoms of the condition for themselves.

\section{CAUSES OF T2DM}

The five risk factors for T2DM identified by participants included: diet, genetics, physical activity, sedentary time and body weight. Almost all mentioned diet to be the key risk factor, focusing on the effects of high-sugar consumption: 
Table 2 Results from the UK Diabetes and Diet Questionnaire for 63 South Asian men participating in this study

\begin{tabular}{|c|c|c|c|c|c|}
\hline Questionnaire item & Mean score (SD) & $95 \% \mathrm{Cl}$ & $\begin{array}{l}\text { Median } \\
\text { score (IQR) }\end{array}$ & $\begin{array}{l}\text { Equivalent categorical } \\
\text { score }\end{array}$ & $\begin{array}{l}\text { No }(\%) \text { of } \\
\text { participants } \\
\text { achieving 'healthy' } \\
\text { scores* }^{*}\end{array}$ \\
\hline Vegetables $\dagger$ & $3.65(0.94)$ & 3.42 to 3.89 & $4(3-4)$ & $1-2$ times a day & $45(71.4)$ \\
\hline Fruit† & $3.51(1.15)$ & 3.22 to 3.80 & $4(3-4)$ & $1-2$ times a day & $43(68.3)$ \\
\hline Cakes and biscuits $\ddagger$ & $3.30(1.29)$ & 2.98 to 3.63 & $4(3-4)$ & Once a week or less often & $36(57.1)$ \\
\hline Chocolate and sweets $\ddagger$ & $3.73(1.31)$ & 3.40 to 4.06 & $4(3-5)$ & Once a week or less often & $45(71.4)$ \\
\hline Sweet drinks $\ddagger$ & $2.16(1.75)$ & 1.72 to 2.60 & $1(1-4)$ & 1-2 times a day & 19 (30.2) \\
\hline Full-fat spread $\neq$ & $4.13(1.09)$ & 3.85 to 4.40 & $4(4-5)$ & Once a week or less often & $49(77.8)$ \\
\hline High-fat cheese§ & $3.49(1.12)$ & 3.21 to 3.77 & $3(3-5)$ & Once a week & $30(47.6)$ \\
\hline Processed meat§ & $4.00(1.14)$ & 3.71 to 4.29 & $5(3-5)$ & Never or very rarely & $37(58.7)$ \\
\hline Salted snacks§ & $2.48(1.06)$ & 2.21 to 2.74 & $2(2-3)$ & $2-5$ times a week & $11(17.5)$ \\
\hline Savoury pastries§ & $3.57(0.91)$ & 3.34 to 3.80 & $4(3-4)$ & Less than once a week & $33(52.4)$ \\
\hline Fast foods§ & $3.43(1.00)$ & 3.18 to 3.68 & $3(3-4)$ & Once a week & $29(46.0)$ \\
\hline Puddings§ & $3.75(1.16)$ & 3.45 to 4.04 & $4(3-5)$ & Less than once a week & $40(63.5)$ \\
\hline AlcoholØ & $4.21(1.12)$ & 3.92 to 4.49 & $5(3-5)$ & Less than once a week & $44(69.8)$ \\
\hline Oily fish ${ }^{\star *}$ & $1.84(1.85)$ & 1.38 to 2.31 & $2(0-4)$ & Less than once a week & $19(30.2)$ \\
\hline 3-4 meals/day $\dagger \dagger$ & $4.10(1.54)$ & 3.71 to 4.48 & $5(4-5)$ & Every day & $48(76.2)$ \\
\hline Breakfast†† & $4.27(1.43)$ & 3.91 to 4.63 & $5(4-5)$ & Every day & $50(79.4)$ \\
\hline High-fat/sugar snackł‡ & $2.86(1.50)$ & 2.48 to 3.24 & $3(2-4)$ & Once a week & $23(36.5)$ \\
\hline High-fibre bread§§ & $4.08(1.32)$ & 3.75 to 4.41 & $5(4-5)$ & All of the time & $48(76.2)$ \\
\hline High-fibre cereal§§ & $4.11(1.80)$ & 3.66 to 4.56 & $5(4-5)$ & All of the time & $52(82.5)$ \\
\hline Type of milkףी & $2.17(1.78)$ & 1.73 to 2.62 & $3(0-3)$ & Semiskimmed & $9(14.3)$ \\
\hline UKDD score & $3.44(0.43)$ & 3.33 to 3.55 & $4(3-4)$ & & $34(54.0)$ \\
\hline
\end{tabular}

*Healthy defined as a score of 4 or 5 (A or B).

†Never/very rarely, 0; once a week or less, 1; 2-4 times a week, 2; 5-6 times a week, 3; 1-2 times a day, 4; 3 or more times a day, 5. $\ddagger$ Never/very rarely, 5; once a week or less, 4; 2-4 times a week, 3; 5-6 times a week, 2; 1-2 times a day, $1 ; 3$ or more times a day, 0 . $\S N$ Never/very rarely, 5; less than once a week, 4; once a week, 3; 2-5 times a week, 3; nearly every day or daily, 1; twice or more per day, 0. \Never/very rarely, 5; less than once a week, 5; once a week, 3; 2-5 times a week, 3; nearly every day or daily, 1; twice or more per day, 0. ${ }^{* *}$ Never, 0 ; less than once a week, 1 ; once a week, 4; twice or more per week, 5.

††Never/very rarely, 0; less than once a week, 1; once a week, 2; 2-4 times a week, 3; 5-6 times a week, 4; every day, 5.

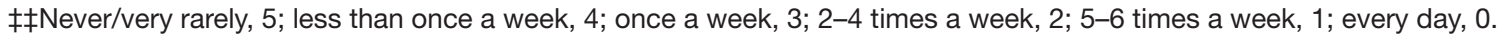
$\S \S A l l$ of the time, 5; most of the time, 4; about half the time, 3; less than half the time, 1; never, 0; I did not eat bread/cereal, 5; ףाFull fat, 0; semiskimmed, 3; skimmed, 5; varies, 2; non-dairy milk, 5; none, 5.

UKDDQ , UK Diabetes and Diet Questionnaire.

Sometimes eating too much sugar in your diet, and also it can be hereditary where even if you don't eat too much sugar you can probably have it as well. (33 years, Indian, Hindu, living in the UK for 33 years)

\section{HOW MUCH CAN AN INDIVIDUAL DO TO PREVENT T2DM?}

All participants agreed to some extent that an individual could act to prevent developing T2DM. The combination of diet and exercise was perceived to be the best way to prevent T2DM:

To prevent, right, is, ah, the best thing, that the healthy diet and the exercise, burning, so if you're burning calories which you're consuming, it's the right balance of it. If it is not balanced, then it can go to diabetes. (46 years, Indian, Sikh, living in the UK for 27 years)

\section{PERCEPTION OF 'HEALTHY' VERSUS 'UNHEALTHY' EATING AND DIET TO PREVENT T2DM}

In general participants were aware of general dietary guidelines. When asked what they considered to be 'healthy eating,' most mentioned the benefits of reducing sugar and fat intake, along with increasing fruit and vegetable intake:

Healthy eating is lots of fruits, vegetables, ah, leafy green vegetables and ah, less of cakes and biscuits and crisps. (41 years, Indian, Hindu, living in the UK for 11 years) 
Others expanded further by considering the importance of portion control in a healthy diet:

I mean, healthy eating is, err, you know, you eat whatever you like but, you know, you're in control. In control...err, in control the portions, err, where whatever you eat you can burn it off then you can eat anything you want, right. (47 years, Indian, Hindu, 15 years)

In contrast, lack of portion control was identified as an important contributor to 'unhealthy eating':

Unhealthy eating is, uh, I'd say, binge eating like, you know, eating a lot of takeaways and, uh, uh, there's not time to, you know, set time for your meals, no set portions and, literally all the junk food... (30 years, Indian, Sikh, living in the UK for 5 years)

\section{FACILITATORS TO MAKING CHANGES}

Participants typically regarded confidence and intrinsic motivation as important facilitators to making change:

Uh, I think, I have to be more confident. Selfdetermination I think and that's the most important thing. (49 years, Indian, Sikh, living in the UK for 30 years)

Family support, particularly in relation to food choice and preparation, was an important theme, with wives having particular influence:

I think what my wife cooks, I think her support is quite critical. Which is I think is true for all South Asians, or for that matter everybody I guess who's married, and whose food [consumption] is dependent on what their partner cooks. (37 years, Indian, Hindu, living in the UK for 5 years)

\section{BARRIERS TO MAKING CHANGES}

A lack of motivation was the main theme most commonly mentioned as a barrier to making positive dietary changes:

I am willing, it just comes down to laziness and having the motivation to stick to it. (...)...I'll do it [healthy eating] for two or three days and then they'll be a day when I'm really craving for sugar. (33 years, Indian, Hindu, living in the UK for 33 years)

Time constraints, in particular related to work, were seen as a limiting factor in making dietary changes:

It's the travelling and ...the work-related timing issues would make difficult for following the diet. (47 years, Indian, Hindu, 15 years)

Cultural commitments emerged as an issue of particular importance when trying to make changes:

My factors I'd say uh, commitments as per, cultural commitments are concerned. You know, we [have] a lot of family events, ceremonies and stuff and 
then it becomes very hard for us to sort of get out of that. I mean, an example, was before and after the [his] wedding. Before [when] I was single and, could sort of escape and, you know, have my control of my diet, but once, you know, [you marry and] get into that routine where you might invite over someone else, guests, we do invitations, a lot of invitations, will go out for a lot of dinners or a lot of people coming around for dinners and that's that for like two or three times a week...we just literally lavish out in our eating and drinking. (30 years, Indian, Sikh, 5 years)

\section{INFLUENCE OF SOUTH ASIAN BACKGROUND}

The majority of men believed that their South Asian background has a significant effect on their dietary habits. The common perception by 20 of the men $(55.5 \%)$ was that the typical South Asian diet was an unhealthy diet:

I think is South Asian food is, is, especially Indian food is really, really rich food. (49 years, Indian, Sikh, living in the UK for 30 years)

In relation to the context of the South Asian diet, the long-term habits of being accustomed to eating certain

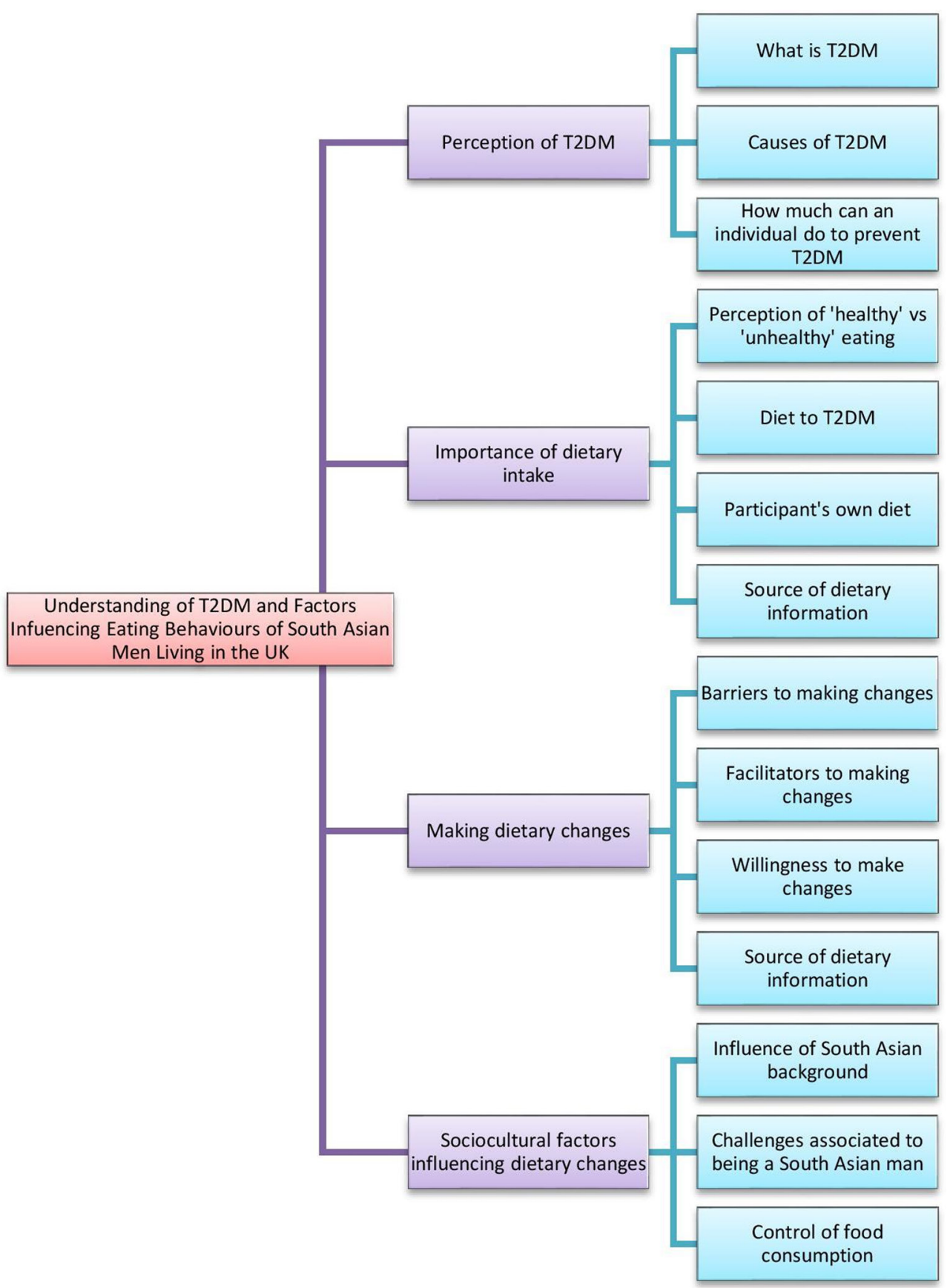

Figure 1 Diagram showing the final coding matrix identifying the key factors influencing dietary behaviours in 36 participants who participated in semistructured qualitative interviews. 
foods was something that many believed would be difficult to change:

It's um, the nature of the food we eat. Someone had told me it is like, food is one thing which you never give up, you can change yourself, culturally or everywhere, that's the bit which is the hardest to give up. (45 years, Indian, Hindu, living in the UK for 11 years)

Another major theme revolved around the impact of festivals and social events on the participant's diet, as illustrated in the following quotes:

I think it is a big part, and also the type of food, ah, which gets given. So we had Diwali, which is one of the biggest festivals... it's now that I think about it, after having discussed with you, I'm struggling to find anything which would be healthy during that period. It's all very sweet, or deep fried, and would have a lot of fat and sugar. And...the festival lasts for I think, three or four days, but the festivities go on for a week or two, and you keep having that all. So that is fat or sugar enough, which you would eat, would normally have in the span of three months... (41 years, Indian, Hindu, 11 years living in the UK)

We pig out on festivals so you should ask them to count the number of festivals they're on and occasions and there are a lot. So, for like 365 days you'll find, like, 100 days you're pigging out. And then... and that you probably consume, like, 5000 calories during that time. And they say, oh, it's just like a festival but, no, it's actually much, much more than what people think. (34 years, Indian, Hindu, living in the UK for 18 years)

Some also made reference to the belief that the differences in climate in the UK compared with the climate in South Asia plays a role in the increased risk of developing T2DM:

So there, because, I mean, it's the hot weather, you consume, you go out, energy burning, sweating and everything, you... is all... most of the energy is burnt in sweating and... but in the cold countries, the problem is that there is no sweating, there's no heat coming out from your body, and everything dump inside, and our skin is blocked, so that cause more problems inside when you consume and you don't burn. (47 years, Indian, Sikh, living in the UK for 27 years)

\section{CHALLENGES ASSOCIATED TO BEING A SOUTH ASIAN MAN}

The main theme that emerged was the lack of control South Asian men believed they had over their food preparation:

Most men don't cook, um, most of the times their wives cook. Many of them [wives] work but many of them don't work... To the extent your wife is not working what tends to happen is they try to make the food taste nice because, you know, (...) which means high fat, high salt, high sugar. (34, Indian, Hindu, living in the UK for 18 years)

\section{CONTROL OF FOOD CONSUMPTION}

The majority of married men (28/29 or $96.6 \%)$ reported that their wives were primarily responsible for cooking at home, with only one married man reporting he is the main cook in the household. Additionally, 78.6\% (22/28) stated that their wives were predominantly responsible for doing the grocery shopping. Furthermore, some participants emphasised their preference for their wives to take responsibility, often believing that their wives were more informed to make better decisions when it came to food selection:

It's normally my wife [who does the food shopping], but because she does it, it's actually controlled, because she's well and truly on top of it, not just because of my stroke, she has been... she has been doing these kind of things for the last 10 years. (45 years, Indian, Hindu, living in the UK for 11 years)

\section{SUITABILITY OF THE UKDDQ}

All of the men stated that UKDDQ was suitable for use in people from a South Asian background. However, suggestions were made for how the tool could be culturally tailored to the population. The most common criticism of the tool was a lack of assessment of rice intake, as they stated that rice was more of a staple carbohydrate for some (in contrast to chapattis), dependent on which geographic area of India they were from:

You can add one more question; possibly, on how much rice you eat. Because depending on where in India they are, they're usually either more rice eaters or chapatti eaters. (47 years, Indian, Hindu, living in the UK for 10 years)

Another popular suggestion was the inclusion of a question asking about the type and frequency of 'fried foods,' in particular 'ghee' consumption. Finally, some the men suggested that for the question on sweets consumption, having a list of specific South Asian sweets in the examples section would enable them to better relate to and quantify their own personal consumption.

\section{DISCUSSION}

Our data illustrate that $54 \%$ of participants had a healthy diet based on their total UKDDQ score. Oily fish consumption was low in South Asian men, with $30.2 \%$ of participants reporting 'healthy intakes.' Our data indicated that oily fish was being consumed 'less than once a week,' which is comparable with data from the general adult population in England. ${ }^{23}$ 
Participants' body weight was positively associated with a higher added sugar intake, which has been shown in previous studies in the general population. ${ }^{24}{ }^{25}$ In particular, $69.8 \%$ of the men reported unhealthy intakes of sugar-sweetened beverages. High consumption of sugar-sweetened beverages is commonly associated with increased risk of developing T2DM. ${ }^{26-29}$ IMD rank was positively associated with both 'high-fibre bread' and 'type of milk,' indicating that participants who were less deprived were more likely to consume high-fibre bread and skimmed/non-fat milk. Alternatively, participants that were more deprived were more likely to consume full-fat spreads. This is supported by previous literature highlighting that higher socioeconomic status is often associated with healthier diets in the general population. ${ }^{30} 31$

The qualitative findings support existing evidence that participants' understanding of T2DM is significantly shaped by the experiences of close friends and family who have the condition. ${ }^{32}$ Results from a recent systematic review ${ }^{33}$ suggest that South Asians have limited knowledge about the relationship between lifestyle and disease risks. In particular, a study by Rankin and Bhopal found that in a mixed sample of 334 UK South Asians, $22 \%$ were unable to identify any risk factors for T2DM. ${ }^{34}$ In contrast, participants in the present study exhibited a good understanding of the main lifestyle-related risk factors contributing to the development of T2DM, with diet, body weight, physical activity and sedentary time identified. One explanation for this discrepancy may be the relatively high education level of our participants, in addition to their high level of self-reported English literacy that likely contributed to their relatively good knowledge about T2DM and related risk factors. ${ }^{35}$ Also, the mean IMD rank of our participants places our sample in the middle $(50.7 \%)$ of the rank of least to most deprived in England. This is in contrast to previous diet-related research conducted in South Asian adults, which has focused on participants from more deprived backgrounds. ${ }^{13} 21323336$ Therefore, our study provides insights into a segment of the South Asian population not previously represented in the literature.

Lack of time, motivation and cultural commitments were identified as the main barriers preventing South Asian men from making positive dietary changes. Lack of time and low motivation are also commonly reported barriers to dietary changes in White populations. ${ }^{37} 38$ Existing research has previously highlighted the role of cultural commitments as a barrier to dietary change in South Asians. ${ }^{39-41}$ The high frequency of these cultural events was a point reinforced by the men in our sample and illustrates that the high frequency and lengthy duration of these events each year are major contributors to the overconsumption of less healthy foods.

Intrinsic motivation emerged as a key factor influencing dietary change, with almost all participants believing that it was up to them, first and foremost, to make changes. This finding is contrast to some previous research in
South Asian populations in which participants commonly expressed a sense of externalisation of responsibility, often citing 'fate' and 'God' as factors influencing the development of their health condition, and as a result, they exhibit a limited degree of personal responsibility. ${ }^{39}{ }^{40} \mathrm{In}$ contrast, results reported by Kristiansen et al found 'hope' and little fatalism in Sikhs and Muslims with life-limiting illnesses. ${ }^{42}$ However, this finding may not be generalisable to our sample as the men participating in our study were not experiencing life-limiting illnesses, and their perceptions and outlook on life are likely different from people who are at the end of their lives. The theme of 'fatalism' reported in some studies of South Asians was non-existent in our sample, with no participants externalising any responsibility for their health. Although some believed that they could only do so much to prevent T2DM, all believed that making changes to their lifestyles would have significant protective effects.

The perceived lack of control that men have over their food preparation was also a key finding from the present study. This supports previous research indicating that South Asian men are reliant on their wives/mothers to do the cooking at home. ${ }^{32}$ It is of interest to note that during the administering of the UKDDQ some men requested that their wives be present in order to confirm their frequency of consumption of certain food items, believing that their wives were more aware of their diets than they were.

The majority of men in the present studied stated the belief that being from a South Asian background affects their eating behaviours. A common theme was the role of cultural events, including religious events and weddings, which play an integral role in South Asian communities and families. These events are perceived as periods when men have little or no control over how food is prepared, and there is a distinct lack of healthy options available to them to choose from. This is widely supported by previous literature emphasising the impact of festivals and social events on dietary intake in South Asian adults. ${ }^{43} 44$

One of the strengths of the present study is the use of a mixed-methods approach, as it provided a more in-depth exploration of what South Asian men living in the UK understand about T2DM, the foods they are eating and the factors influencing eating behaviours than could be derived by using quantitative or qualitative methods in isolation. This was also the first study to have assessed diet in South Asian men living in the UK using the newly developed and validated UKDDQ, which has been specifically designed for use with people at risk of, or with, T2DM living in the UK. Using this questionnaire allowed the researchers to focus on foods and behaviours that have been shown to be directly linked with weight loss and also served as a mechanism to stimulate rich conversations about diabetes prevention and healthy changes that could be made to their current dietary intake. The participants in the present study indicated that they felt this tool was appropriate and useful for South Asians, and useful insights were gained as to how the tool could be further 
culturally tailored to the population. A version of UKDDQ that names specific South Asian sweets, includes ghee and makes it explicit that lentils and pulses (legumes) should be included as vegetables is now available (https://sps. onlinesurveys.ac.uk/the-uk-diabetes-and-diet-questionnaire-ukddq).

However, this study is not without limitations. The cross-sectional nature of this study provides only a snapshot of dietary intake in this sample. Due to the relatively small sample size, our findings may not be generalisable to the wider population of South Asian men living in the UK. Although we used maximum variation sampling to recruit our participants, engaging with mosques and Muslim community centres proved to be very challenging, which is why we were unable to recruit as many Muslims and men from Pakistan as originally planned. Participants in our study were also highly educated, with $81 \%$ having a university degree, which may also limit the generalisability of our findings. However, $87.3 \%$ of the participants in our sample were Indian, with a further $71.4 \%$ being Indian immigrants. UK Indians are 1.5 times more likely to hold a degree than white British adults; furthermore, $54 \%$ of UK Indian immigrants between the ages of 25-49 years are university graduates. ${ }^{45}$ Therefore, UK Indians are a highly educated minority group. Although some public health studies in the UK have included proportional amounts of Indians in their samples, ${ }^{4647}$ others have not, ${ }^{2148-50}$ despite them being the most populous South Asian subgroup in the UK. Therefore, we believe this sample is reflective of a significant portion of the UK South Asian population who have not consistently been represented in the literature.

This study revealed additional information about the unique sociocultural challenges that overweight and obese South Asian men face when trying to make positive dietary changes, and as such healthcare professionals should be aware of these when implementing strategies to improve diet in this population. Further research using UKDDQ in larger, representative samples of South Asians and other populations in the UK is needed, to allow for comprehensive comparisons to be made. Additionally, feedback on the suitability of using UKDDQ provides support for the use of this newly developed questionnaire in this population, and useful insights were gained as to how the questionnaire can be culturally tailored to meet the needs of the population. A priority for future studies includes conducting a systematic review to bring together existing data on dietary intake in UK South Asians to aid in our understanding of the current dietary characteristics of the population.

\section{CONCLUSION}

Findings from this study illustrated that $54 \%$ of this sample of highly educated overweight and obese South Asian men living in the UK had healthy diets. However, from the dietary information gathered, diets were not too dissimilar to the general adult male population in England. Given that $69.8 \%$ had unhealthy intakes of sugar-sweetened beverages, along with the previous data demonstrating the association between sugar-sweetened beverage consumption and T2DM, healthcare professionals should target reducing their consumption in UK South Asian men. In addition, there is scope to develop healthy-eating advice targeting the frequency and duration of cultural events in which this population regularly engages.

Acknowledgements We thank the community leaders and participants for participating in this study.

Contributors AE and JLT designed the research. AE collected the data. AE, JLT and CYE analysed the data. AE and JLT developed the initial draft of the paper. All authors reviewed multiple drafts of the paper and approved the final manuscript for submission.

Funding This study is part of the self-funded $\mathrm{PhD}$ research of Amir Emadian, with some support from the School of Sport, Exercise and Rehabilitation Sciences at the University of Birmingham.

Competing interests None declared.

Patient consent Detail has been removed from this case description/these case descriptions to ensure anonymity. The editors and reviewers have seen the detailed information available and are satisfied that the information backs up the case the authors are making.

Ethics approval Ethical review committee of the University of Birmingham. Provenance and peer review Not commissioned; externally peer reviewed. Data sharing statement No additional data are available.

Open Access This is an Open Access article distributed in accordance with the Creative Commons Attribution Non Commercial (CC BY-NC 4.0) license, which permits others to distribute, remix, adapt, build upon this work non-commercially, and license their derivative works on different terms, provided the original work is properly cited and the use is non-commercial. See: http://creativecommons.org/ licenses/by-nc/4.0/

(C) Article author(s) (or their employer(s) unless otherwise stated in the text of the article) 2017. All rights reserved. No commercial use is permitted unless otherwise expressly granted.

\section{REFERENCES}

1. Statistics UK http://www.statistics.gov.uk/cci (accessed Oct 2016)

2. Ntuk UE, Gill JM, Mackay DF, et al. Ethnic-specific obesity cutoffs for diabetes risk: cross-sectional study of 490,288 UK biobank participants. Diabetes Care 2014;37:2500-7.

3. Barnett AH, Dixon AN, Bellary S, et al. Type 2 diabetes and cardiovascular risk in the UK South Asian community. Diabetologia 2006;49:2234-46.

4. Tillin T, Sattar N, Godsland IF, et al. Ethnicity-specific obesity cutpoints in the development of type 2 diabetes - a prospective study including three ethnic groups in the United Kingdom. Diabet Med 2015;32:226-34.

5. Sattar N, Gill JM. Type 2 diabetes in migrant South Asians: mechanisms, mitigation, and management. Lancet Diabetes Endocrinol 2015;3:1004-16.

6. Misra A, Ramchandran A, Jayawardena R, et al. Diabetes in South Asians. Diabet Med 2014;31:1153-62.

7. Bhopal RS. A four-stage model explaining the higher risk of Type 2 diabetes mellitus in South Asians compared with European populations. Diabet Med 2013;30:35-42.

8. Misra A, Khurana L, Isharwal S, et al. South Asian diets and insulin resistance. Br J Nutr 2009;101:457-73.

9. Donin AS, Nightingale CM, Owen CG, et al. Nutritional composition of the diets of South Asian, black African-Caribbean and white European children in the United Kingdom: the Child Heart and Health Study in England (CHASE). Br J Nutr 2010;104:276-85.

10. Sevak L, Mangtani P, McCormack V, et al. Validation of a food frequency questionnaire to assess macro- and micro-nutrient intake among South Asians in the United Kingdom. Eur J Nutr 2004;43:160-8. 
11. Simmons D, Williams R. Dietary practices among Europeans and different South Asian groups in coventry. Br J Nutr 1997;78:5-14.

12. Kassam-Khamis T, Judd PA, Thomas JE. Frequency of consumption and nutrient composition of composite dishes commonly consumed in the UK by South Asian Muslims originating from Bangladesh, Pakistan and East Africa (Ismailis). J Hum Nutr Diet 2000;13:185-96.

13. Chapman J, Qureshi N, Kai J. Effectiveness of physical activity and dietary interventions in South Asian populations: a systematic review. Br J Gen Pract 2013;63:104-14.

14. Emadian A, Thompson J. A mixed-methods examination of physical activity and sedentary time in overweight and obese South Asian men living in the United Kingdom. Int J Environ Res Public Health $2017 ; 14: 348$

15. Teddlie C, Yu F. Mixed methods sampling: a typology with examples. J Mix Methods Res 2007;1:77-100.

16. UK Government. English index of multiple deprivation. https://www. gov.uk/government/statistics/english-indices-of-deprivation-2015 (accessed October 2016).

17. England CY, Thompson JL, Jago R, et al. Development of a brief, reliable and valid diet assessment tool for impaired glucose tolerance and diabetes: the UK diabetes and diet questionnaire. Public Health Nutr 2017;20:1-9.

18. Templeton GF. A two-step approach for transforming continuous variables to normal: implications and recommendations for IS research. Commu Assoc Inf Syst 2011;28:41-58.

19. Sterne JA, Smith GD. Sifting the evidence-what's wrong with significance tests? Phys Ther 2001;81:1464-9.

20. Hsieh HF, Shannon SE. Three approaches to qualitative content analysis. Qual Health Res 2005;15:1277-88.

21. Cross-Bardell L, George T, Bhoday M, et al. Perspectives on enhancing physical activity and diet for health promotion among at-risk urban UK South Asian communities: a qualitative study. BMJ Open 2015;5:e007317.

22. Hempler NF, Nicic S, Ewers B, et al. Dietary education must fit into everyday life: a qualitative study of people with a Pakistani background and type 2 diabetes. Patient Prefer Adherence 2015;9:347.

23. Public Health England. https://www.gov.uk/government/statistics/ ndns-results-from-years-5-and-6-combined (accessed Oct 2016).

24. Malik VS, Schulze MB, Hu FB. Intake of sugar-sweetened beverages and weight gain: a systematic review. Am J Clin Nutr 2006;84:274-88.

25. Wang $\mathrm{H}$, Steffen LM, Zhou X, et al. Consistency between increasing trends in added-sugar intake and body mass index among adults: the Minnesota Heart Survey, 1980-1982 to 2007-2009. Am J Public Health 2013;103:501-7.

26. Malik VS, Hu FB. Sweeteners and risk of obesity and type 2 diabetes: the role of sugar-sweetened beverages. Curr Diab Rep 2012;12:195-203.

27. Imamura F, O'Connor L, Ye Z, et al. Consumption of sugar sweetened beverages, artificially sweetened beverages, and fruit juice and incidence of type 2 diabetes: systematic review, meta-analysis, and estimation of population attributable fraction. Br J Sports Med 2016;50:496-504.

28. O'Connor L, Imamura F, Lentjes MA, et al. Prospective associations and population impact of sweet beverage intake and type 2 diabetes, and effects of substitutions with alternative beverages. Diabetologia 2015;58:1474-83.

29. Ma J, Jacques PF, Meigs JB, et al. Sugar-sweetened beverage but not diet soda consumption is positively associated with progression of insulin resistance and prediabetes. J Nutr 2016;146:2544-50.

30. Maguire ER, Monsivais P. Socio-economic dietary inequalities in UK adults: an updated picture of key food groups and nutrients from national surveillance data. Br J Nutr 2015;113:181-9.
31. Darmon N, Drewnowski A. Does social class predict diet quality? Am J Clin Nutr 2008;87:1107-17.

32. Grace C, Begum R, Subhani S, et al. Prevention of type 2 diabetes in British Bangladeshis: qualitative study of community, religious, and professional perspectives. BMJ 2008;337:a1931.

33. Lucas A, Murray E, Kinra S. Heath beliefs of UK South Asians related to lifestyle diseases: a review of qualitative literature. $J$ Obes 2013;2013:1-13.

34. Rankin J, Bhopal R. Understanding of heart disease and diabetes in a South Asian community: cross-sectional study testing the 'snowball' sample method. Public Health 2001;115:253-60.

35. Islam SM, Niessen LW, Seissler J, et al. Diabetes knowledge and glycemic control among patients with type 2 diabetes in Bangladesh. Springerplus 2015;4:1-7.

36. Choudhury SM, Brophy S, Williams R. Understanding and beliefs of diabetes in the UK Bangladeshi population. Diabet Med 2009;26:636-40.

37. Kearney JM, McElhone S. Perceived barriers in trying to eat healthier - results of a pan-EU consumer attitudinal survey. Br J Nutr 1999;81(S1):S133-7.

38. Booth $A O$, Lowis $C$, Dean $M$, et al. Diet and physical activity in the self-management of type 2 diabetes: barriers and facilitators identified by patients and health professionals. Prim Health Care Res Dev 2013;14:293-306.

39. Lawton J, Ahmad N, Hanna L, et al. 'I can't do any serious exercise': barriers to physical activity amongst people of Pakistani and Indian origin with type 2 diabetes. Health Educ Res 2006;21:43-54.

40. Darr A, Astin F, Atkin K. Causal attributions, lifestyle change, and coronary heart disease: illness beliefs of patients of South Asian and European origin living in the United Kingdom. Heart Lung 2008;37:91-104.

41. Sohal T, Sohal P, King-Shier KM, et al. Barriers and facilitators for type-2 diabetes management in South Asians: a systematic review. PLoS One 2015;10:e0136202.

42. Kristiansen M, Irshad T, Worth A, et al. The practice of hope: a longitudinal, multi-perspective qualitative study among South Asian Sikhs and Muslims with life-limiting illness in Scotland. Ethn Health 2014;19:1-19.

43. Stone M, Pound E, Pancholi A, et al. Empowering patients with diabetes: a qualitative primary care study focusing on South Asians in Leicester, UK. Fam Pract 2005;22:647-52.

44. Keval H. Cultural negotiations in health and illness: the experience of type 2 diabetes among Gujarati-speaking South Asians in England. Divers Health Care 2009;6:255-65.

45. Lymperopoulou K, Parameshwaran M. How are ethnic inequalities in education changing. centre on dynamics of ethnicity. $2014 \mathrm{http}: / /$ www. ethnicity. ac. uk/medialibrary/briefingsupdated/how-areethnicinequalities-in-education-changing. pdf (accessed Mar 2014).

46. Bhopal RS, Douglas A, Wallia S, et al. Effect of a lifestyle intervention on weight change in South Asian individuals in the UK at high risk of type 2 diabetes: a family-cluster randomised controlled trial. Lancet Diabetes Endocrinol 2014;2:218-27.

47. Pollard TM, Carlin LE, Bhopal R, et al. Social networks and coronary heart disease risk factors in South Asians and Europeans in the UK. Ethn Health 2003;8:263-75.

48. Curry WB, Duda JL, Thompson JL. Perceived and objectively measured physical activity and sedentary time among South Asian women in the UK. Int J Environ Res Public Health 2015;12:3152-73.

49. Iqbal G, Johnson MR, Szczepura A, et al. UK ethnicity data collection for healthcare statistics: the South Asian perspective. BMC Public Health 2012;12:243.

50. Horne M, Skelton DA, Speed S, et al. Perceived barriers to initiating and maintaining physical activity among South Asian and White British adults in their 60s living in the United Kingdom: a qualitative study. Ethn Health 2013;18:626-45. 